\title{
Análise geral sobre Problemas de Horários Educacionais tratados no Brasil
}

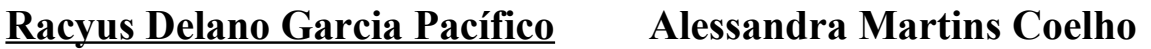 \\ Instituto Federal de Educação, Ciência e Tecnologia do \\ Sudeste de Minas Gerais - Departamento Acadêmico de Ciência da Computação, \\ 36180-000, Câmpus Rio Pomba \\ e-mail: racyus.delano@ifsudestemg.edu.br \\ alessandra.coelho@ifsudestemg.edu.br
}

\begin{abstract}
RESUMO
A evolução dos computadores fez com que muitos problemas complexos encontrados no dia a dia começassem a ser solucionados via algoritmos computacionais. Na década de 60 , trabalhos como os de [3], [5] e [6] impulsionaram as pesquisas sobre modelagem e automação de Problemas de Horários Educacionais (PHE). Desde então, devido aos tipos de restrições encontradas nas instituições, várias modelagens já foram realizadas e, conforme uma classificação proposta por [1], PHEs podem ser enquadrados em uma das três categorias: Problemas de Horários Escolares ou Problema Classe-Professor (PHCP), Problemas de Horários Universitários (PHU) ou Problemas de Horários de Cursos (PHC) e Problema de Horário de Exames (PHEx).

O PHCP básico consiste em, a partir de um conjunto (turma ou classe) homogêneo de estudantes de um mesmo currículo, um conjunto de professores com uma carga-horária semanal para cada disciplina a ser ministrada para cada turma e um conjunto de períodos de tempo distribuídos entre os dias da semana, agendar somente um encontro entre um professor e uma classe, num determinado período de tempo. Ao contrário do que acontece com o $\mathrm{PHCP}$, o PHU pode conter estudantes de currículos diferentes realizando a mesma disciplina (curso). Se duas disciplinas possuírem estudantes em comum e seus horários conflitam, então elas não poderão ser agendadas para o mesmo período. Já o PHEx é semelhante ao PHU, diferindo desse pelo tipo de restrições impostas [2].

A solução manual de um PHE normalmente requer vários dias de dedicação e nem sempre é considerada uma tarefa fácil entre os profissionais que elaboram os quadros de horários. Muitos fatores podem contribuir para o aumento da complexidade, como o número de classes ou cursos, professores e tipos restrições impostas ao problema. Além disso, apesar de todo o esforço e da consequente obtenção de um quadro de horários que, de fato, é utilizado pela instituição de ensino envolvida, o resultado final pode não ser tão satisfatório, pois nem sempre é possível atender às solicitações dos professores para a programação de suas aulas, acarretando insatisfação de alguns [2].

Apesar de softwares, como Cronos [4], Urânia [9], TimeS'cool [8] e outros serem destinados à elaboração de quadros de horários, na maioria das vezes, esses tratam somente das restrições gerais do problema, não conseguindo atender a certas restrições que são específicas de determinadas instituições, para que um horário seja efetivamente utilizado.

Visando compreender as modelagens de PHEs no Brasil, foi realizado um levantamento, observando os tipos de dados, tamanho do problema, número de turnos trabalhados em simultâneo, tipo de problema abordado, formas de resolução e restrições tratadas. Percebeu-se que muitos desses trabalhos são carentes de informações, como: a modelagem do problema estudado, se a abordagem foi testada com dados reais ou fictícios, tipos de restrições utilizadas, dentre outras.

Foram analisados 32 trabalhos [7], sendo em sua grande maioria relacionados a escolas secundárias ou universidades que possuem o mesmo perfil de distribuição de aulas semanais.
\end{abstract}


Desses, nove trabalhos usaram dados fictícios, 19 dos 32 trabalhos não continham informações sobre o número de turnos tratados ao mesmo tempo. Metaheurísticas foram utilizadas para resolução da maioria dos casos.

Como trabalho futuro pretende-se ampliar o número de trabalhos analisados e realizar um levantamento das restrições tratadas, a fim de delimitar o perfil das pesquisas relacionadas com Problemas de Horários Educacionais no Brasil e a complexidade dos mesmos.

Palavras-Chave: Problemas de Horário Educacional, Timetabling

Agradecimento: Os autores agradecem à FAPEMIG e ao IF SUDESTE MG pelo apoio.

\section{Referências}

[1] A. A. Schaerf, A. A survey of automated timetabling. Artificial intelligence review, Springer, v. 13, n. 2, p. 87-127, 1999

[2] A. M. Coelho. "Uma abordagem via algoritmos meméticos para a solução do problema de horário escolar". 2006. 115f. Dissertação (Mestrado em Modelagem Matemática e Computacional). Centro Federal de Educação Tecnológica do estado de Minas Gerais, Belo Horizonte, 2006.

[3] C. C. Gotlieb. The construction of class-teacher time-tables. In: IFIP Congress, 1962. p. 7377.

[4] CRONOS. Cronos - Geração de horários escolares. 2006. Acessado em 23/04/2014. Disponível em: $<$ http://www.sistemacronos.com.br $>$.

[5] J. Appleby; D. Blake; E. Newman, Techniques for producing school timetables on a computer and their application to other scheduling problems. The Computer Journal, $\mathrm{Br}$ Computer Soc, v. 3, n. 4, p. 237-245, 1961.

[6] M. E. C. Balogh, On scheduling algorithms. 1964.

[7] R. D. G. Pacífico. BRÍGIDA - Ferramenta computacional para geração de quadros de horário educacional para os cursos técnicos integrados do IF Sudeste MG - Câmpus Rio Pomba. 2013. 93 f. Monografia (Ciência da Computação). Instituto Federal de Educação, Ciência e Tecnologia do Sudeste de Minas Gerais, Rio Pomba, 2013.

[8] TIMES'COOL. TimeS'Cool - Horário escolar. 2007. Acessado em 23/04/2014. Disponível em: $<$ http://www.timescool.lotimiza.com>.

[9] URÂNIA. Urânia - O melhor e mais premiado programa para fazer horário escolar. 1988. Acessado em 23/04/2014. Disponível em: <http://www.horario.com.br>. 